\title{
Prevalence of Pfmdr 1 N86Y and Y184F Alleles is Associated with Recurrent Parasitemia following Treatment of Uncomplicated Malaria with Artemether-Lumefantrine in Nigerian Patients
}

\author{
Ayogu Ebere Emilia ${ }^{\mathrm{a}, b^{*}}$, Ukwe Chinwe Victoria ${ }^{\mathrm{b}}$, Mgbeahuruike Anthony Christian $^{\mathrm{c}}$, Nna Emmanuel Okechukwu ${ }^{\mathrm{d}}$ \\ ${ }^{a}$ District Hospital Nsukka, Ministry of Health, Enugu State, Nigeria. ${ }^{b}$ Department of Clinical Pharmacy and Pharmacy Management, Faculty of \\ Pharmaceutical Sciences,University of Nigeria Nsukka, 410001 Nsukka Campus Enugu State Nigeria. ${ }^{\mathbf{c}}$ Department of Microbiology, Faculty of Biological \\ Sciences, University of Nigeria Nsukka, 410001 Nsukka Campus, Enugu State Nigeria. ${ }^{\mathrm{d}}$ Safety Molecular Pathology Laboratory, Faculty of Health \\ Sciences Enugu Campus, Enugu State Nigeria.
}

\section{ARTICLE INFO}

\section{Article history:}

Received on: 08/01/2016

Revised on: 04/03/2016

Accepted on: 28/03/2016

Available online: 30/04/2016

Key words:

Plasmodium falciparum,

artemether-lumefantrine,

Pfmdr 1 gene, genotyping.

\begin{abstract}
We investigated and compared genetic variations in Plasmodium falciparum multidrug resistance 1 gene (Pfmdr 1) in patients showing good therapeutic response (GTR) and artemisinin resistance (AR) following artemetherlumefantrine (AL) treatment of uncomplicated malaria in Nigeria. Some 150 malaria patients were subjected to AL treatment and therapeutic efficacy was monitored for 28 days. Parasite genomic DNA was isolated followed by nested polymerase chain reaction (PCR). Genotyping of Pfmdr 1 gene for specific genetic variants: N86Y, Y184F, S1034C and N1042D were done using PCR-restriction fragment length polymorphism (PCRRFLP).Out of 121 patients that were P. falciparum positive, $46 \%$ (56) and $54 \%$ (65) showed good therapeutic response and artemisinin resistance respectively, with $5.4 \%$ and $98.3 \%$ being mutated in the GTR and AR group respectively. The most prevalent mutations were Y184F $(44.1 \%)$ and N86Y $(40.7 \%)$. There was significant increase $(\mathrm{p}<0.001)$ in the prevalence of $P f m d r 1$ mutation in the post treatment compared to the pretreatment group.Prevalence of $P f m d r 186 \mathrm{Y}$ and $184 \mathrm{~F}$ alleles is associated with artemisinin resistance and presence of AL drug significantly induced genetic variation in the plasmodial gene.
\end{abstract}

\section{INTRODUCTION}

Malaria is the world's most widely spread parasitic infection with 1-2 million deaths attributable to the disease annually (Guerra et al., 2006; Hay et al., 2004; Snow et al., 2005). Nineteen countries in Africa, including Nigeria, account for $90 \%$ of all WHO estimated cases of malaria in 2006 (UK Aid Department for International Development, 2010). More than half of all the estimated world malaria cases occurred in Nigeria and India (Hay et al., 2007). Malaria imposes great burden in terms of pain and trauma suffered by its victims as well as loss in output and cost of treatment (Onwujekwu et al., 2007). Every year, Nigeria loses over 132 billion Naira (over \$1 billion) from

* Corresponding Author

Ebere Emilia Ayogu, Clinical Pharmacy and Pharmacy Management,

University of Nigeria, Nsukka, Nigeria. Email: ebereayogu[at]yahoo.com the cost of treatment and absenteeism from work due to malaria attack (Federal Ministry of Health, 2005). P. falciparum has also become the predominant malaria specie in many parts of the world (Guerra et al., 2006) and continues to be a major threat to travelers to tropical regions (Mayxay et al., 2004).

There is accumulating evidence to show that the therapeutic efficacy of Chloroquine (CQ) and Sulfadoxine pyrimethamine (SP), the major drugs for treatment of uncomplicated malaria in Nigeriahave deteriorated due to $P$. falciparum resistance (Ezedinachi et al., 1992; Falade et al., 1997; Ekanem et al., 2000). Hence in 2005, Nigerian National Antimalarial Treatment Policy (NNATP) adopted AL as first line treatment of uncomplicated malaria caused by $P$. falciparum in Nigeria (Nosten et al 2007; White, 2008). Antimalarial drug resistance has been associated with specific point mutations in several genes of the Plasmodium falciparum (Duraisingh and Cowman, 2005). 
An important gene; Plasmodium falciparum multidrug resistant gene 1 (Pfmdr1) located on chromosome 5 of the $P$. falciparum genome, which shows similarity to the P-glycoprotein product of the human multidrug resistance gene $m d r$, is strongly associated with resistance to anti-malarial drugs (Rohrbach et al., 2006). The role of genes such as Plasmodium falciparum chloroquine resistance transporter (Pfcrt), Pfmdr1 and Dihydrofolate reductase $(d h f r)$ in antimalarial drug resistance has been studied (Falade et al., 2005). The efficacy and effectiveness of AL as an antimalarial drug has been reported (Falade et al., 2005; Yeka et al 2008; Zurovac et al., 2008). Recent reports from Africa have shown some evidence of clinical and parasitological failure after treatment with AL (Yang et al., 2003; Jambou et al., 2005; Noedl et al., 2010).

Studies have shown that genetic variations like single nucleotide polymorphism (SNPs), mutations and copy number variations $(\mathrm{CNV})$ in such resistance associated genes like Pfmdr1, alter the respective protein structural conformation in the Plasmodium, hence reducing drug binding or altering molecular transport system leading to parasite surviving the drug effect (Duraisingh and Cowman, 2005). Genetic variations at various positions on the Pfmdrl gene (N86Y, Y184F, S1034C, N1042D and D1246Y) have been shown to be associated with resistance to chloroquine, mefloquine, quinine, halofantrine, lumefantrine and artemisinins (Dokomajilar et al., 2006; Sisowath et al., 2005). Recent finding has shown that treatment with the widely advocated AL is associated with selection of newly infecting parasites containing the Pfmdr $186 \mathrm{~N}$ allele (Sisowath et al., 2005). The Y86N allele has been associated with decrease in vitro sensitivity to artemisinins and lumefantrine (Duraisingh et al., 2000a). In this study we investigated and compared genetic variations in Plasmodium falciparum multidrug resistance 1 gene $(P f m d r 1)$ in patients showing good therapeutic response (GTR) and artemisinin resistance (AR) following artemether-lumefantrine (AL) treatment of uncomplicated malaria in Nigeria.

\section{MATERIALS AND METHOD}

\section{Study Area and Sampling}

The study was conducted between April-November, 2013 in three hospitals: the District Hospital Nsukka, Bishop Shanahan Hospital, Nsukka and Cottage Hospital Ugbuawka, all in Enugu State, South- Eastern Nigeria.

The study area has been described elsewhere ${ }^{[25]}$. Out patients of 6 years and above presenting with symptoms indicating acute uncomplicated malaria with a body temperature of $\geq 37{ }^{\circ} \mathrm{C}$ and history of fever in $24-48 \mathrm{~h}$ preceding presentation were enrolled for the study ${ }^{[21]}$. Ethical approval was obtained from the University of Nigeria Teaching -Hospital (UNTH) Health Research Ethics Committee, Enugu. The reference number is NHREC/05/01/2008B-FWA00002458-IRB00002323. Informed consent was obtained from adult participants and from parents for children under their care. Consent was also obtained from patients to publish this information. Patients with history of anti-malarial use 2 weeks before presentation were excluded. Infants and young children below 6 years old were excluded to reduce noncompliance due to vomiting. In addition, patients with complicated malaria, sickle cell anemia, known allergy to study drug, and HIV positive were equally excluded.

\section{Patient's Treatment}

Patients who presented with symptoms such as headache, fever, shivering and vomiting tendency during the past 24 hours to the study hospitals, were examined using thick film microscopy. Their body temperature readings were taken and recorded. The patients received tablets of AL $\left(\right.$ Coartem $^{\circledR}$, Novartis AG, Basel, Switzerland) in the order indicated in Table 1. Each tablet of AL contains $20 \mathrm{mg}$ of artemether and $120 \mathrm{mg}$ of lumefantrine. An easy to fill compliance form with six boxes for ticking at each time drug is taken was designed to help the patients take appropriate dose at the right time, since patients were not in-patients.

All participants were educated on how to tick the compliance form as some were not literate. The compliance form was given to each patient along with drug and was submitted on the next follow up visit on day 3. This was used to monitor patient's compliance.

Table 1: Doses of artemether-lumefantrine drugs for different age ranges and body weight.

\begin{tabular}{|c|c|c|c|c|c|c|c|}
\hline \multirow{3}{*}{$\begin{array}{l}\text { Body } \\
\text { weight } \\
\text { (kg) }\end{array}$} & \multirow{3}{*}{$\begin{array}{l}\text { Age } \\
\text { (years) }\end{array}$} & & & \multicolumn{4}{|c|}{ Duration (Days / Time) } \\
\hline & & \multicolumn{2}{|r|}{1} & \multicolumn{2}{|l|}{2} & \multicolumn{2}{|c|}{3} \\
\hline & & $\mathbf{0 h}$ & $8 \mathrm{~h}$ & $20 \mathrm{~h}$ & 32h & $44 \mathrm{~h}$ & $56 \mathrm{~h}$ \\
\hline $5-14$ & $<3$ & $1 \mathrm{tab}^{\mathrm{a}}$ & $1 \mathrm{tab}$ & $1 \mathrm{tab}$ & $1 \mathrm{tab}$ & $1 \mathrm{tab}$ & $1 \mathrm{tab}$ \\
\hline $15-24$ & $>3-8$ & 2 tab & $2 \mathrm{tab}$ & $2 \mathrm{tab}$ & 2 tab & $2 \mathrm{tab}$ & $2 \mathrm{tab}$ \\
\hline $25-34$ & $>9-14$ & $3 \mathrm{tab}$ & 3 tab & 3 tab & 3 tab & $3 \mathrm{tab}$ & $3 \mathrm{tab}$ \\
\hline$>34$ & $>14$ & $4 \mathrm{tab}$ & $4 \mathrm{tab}$ & $4 \mathrm{tab}$ & $4 \mathrm{tab}$ & $4 \mathrm{tab}$ & $4 \mathrm{tab}$ \\
\hline
\end{tabular}

Doses of artemether-Lumefantrine administered to each patient group in different age brackets and body weights $(\mathrm{kg})$. The treatments were given at different time intervals $(0 \mathrm{hr}, 8 \mathrm{~h}, 20 \mathrm{~h}, 32 \mathrm{~h}, 44 \mathrm{~h}$ and $56 \mathrm{~h})$ in 3 days. ${ }^{a}=$ tablet, each tablet of AL contains artemether, 20mg, lumefantrine, $120 \mathrm{mg}$ ).

\section{DNA Extraction from Blood Samples}

$P$. falciparum genomic DNA was extracted from the blood samples by saponin hemolysis method (Ayogu et al., 2015, Orjih et al., 2008). The purity and quality of the DNA was determined using Eppendorf BioPhotometer Plus (Eppendorf, Germany). The $\mathrm{A}_{260 / 280}$ ratios were between 1.7 - 2.0. The DNA samples were stored at $-20{ }^{\circ} \mathrm{C}$ until required for analysis.

\section{Plasmodium falciparum Detection and Quantification by Nested PCR and Real time PCR}

PCR was used to amplify multiple copies of Plasmodium genomic DNA. The PCR (Applied biosystem 2720, Singapore, S/No 272S1132046) was run in two rounds. Round one was run to detect the genus Plasmodium malaria using a primer set, RI (rPLU5 and rPLU6) of amplicon size, 1200 base pair (bp) (Table 2 ). The PCR product from round one was used in round two in the 
Real time PCR (Applied biosystem StepOne ${ }^{\mathrm{TM}}$, Singapore S/No 271002578) for detection and quantification of Plasmodium falciparum species. For the second round PCR, primer set R2, (rFa11 and rFa12) with amplicon size, 205 bp was used (Table 2). The procedures and thermal profile used have been described elsewhere (Ayogu et al., 2015).

Table 2: Mutation sites and the primer sequences used for nested PCR and genotyping of Pfmdr 1 gene.

\begin{tabular}{|c|c|c|}
\hline$\overline{\text { Gene }}$ & Mutation $^{\mathrm{a}}$ & Primer sequence $^{\mathrm{a}}$ \\
\hline \multirow[t]{7}{*}{ Pfmdr 1} & N86Y & 5'ATGGGTAAAGAGCAGAAAGAG3' \\
\hline & & 5'CGTACCAATTCCTGAACTCAC3' \\
\hline & Y84F & 5'CAAGAAGGAAGTAAGTATCCAAAAATGG3' \\
\hline & & 5'CTGAAGGCATCTAACATGGATATAGC3' \\
\hline & S1034C & 5'CAAGAAGGAAGTAAGTATCCAAAAATGG3' \\
\hline & & 5'CTGAAGGCATCTAACATGGATATAGC3' \\
\hline & N1042D & 5'TATGTCAAGCGGAGTTTTTGC3' \\
\hline \multicolumn{3}{|l|}{ Primer } \\
\hline \multirow[t]{2}{*}{$\mathrm{R} 1$} & rPLU5 & 5'CCTGTTGTTGCCTTAAACTTC3' \\
\hline & rPLU6 & 5’TTAAAATTGTTGCAGTTAAAAC3' \\
\hline \multirow[t]{2}{*}{$\mathrm{R} 2$} & rFal1 & 5’TTAAACTGGTTTGGGAAAACC3’ \\
\hline & $\mathrm{rFal} 2$ & 5'ACACAATGAACTCAATCATGA3' \\
\hline
\end{tabular}

Mutation $=$ Polymorphic sites of Pfmdr 1 gene $(\mathrm{N}=$ asparagine, $\mathrm{F}=$ phenylalanine, $\mathrm{Y}=$ thyrosine, $\mathrm{S}=$ serine, $\mathrm{C}=$ cystein and $\mathrm{D}=$ aspartate) ${ }^{\mathrm{a}}=$ primer sequences specific for each mutation.

\section{Classification of Patients into Two Groups: Good Therapeutic Response and Artemisinin Resistance Group}

Based on the WHO guideline which states that the working definition of artemisinin resistance is an increase in parasite clearance time as evidenced by $\geq 10 \%$ of cases with parasites detectable on day 3 after treatment with an ACT (suspected resistance) (WHO, 2013), patients were grouped into two: those that showed good therapeutic response (GTR) and artemisinin resistance (AL). The two groups of patients were genotyped and the frequency of mutation in the Pfmdr 1 genes compared.

\section{Genotyping of Parasite Genomic DNA for Pfm 1 r 1 Genes}

Genotyping was based on the standardized PCR reaction and restriction fragment length polymorphism (RFLP) based on previous protocols (Thompson et al., 2011) with modifications according to available resources. For amplification of the Pfmdr1 gene coding region, a nested PCR protocol was adopted followed by RFLP.

For the analysis of SNPs in Pfmdr 1 gene, $P$. falciparum laboratory parasite isolate 3D7 was used as positive controls, while negative control was gotten from infants below 6 months that has not been exposed to malaria infection. The PCR was run in two rounds: outer and nested PCR, which were done with a primer pair for amplification of codon 86, 184, 1034 and 1042 of Pfmdr 1 genes where resistance - associated mutations were thought to occur (Table 2).

PCR master mix contained 1:1 TEMPase polymerase (including buffer and dNTP; Thermo Scientific. Germany S/No 00125960) to a final volume of $6.3 \mu \mathrm{l}, 3.7 \mu \mathrm{l}$ of primer for each codon $(86,184,1034$ and 1042) (Table 2) and $2.5 \mu 1$ gDNA were transferred into 96 well PCR plate and capped properly. The PCR was run in a thermal cycler in a reaction volume of $12.5 \mu \mathrm{l}$. The thermal profile was $94{ }^{\circ} \mathrm{C}$ for 15 min followed by 30 cycles at 94 ${ }^{\circ} \mathrm{C}$ for $30 \mathrm{sec}, 5{ }^{\circ} \mathrm{C}$ for $50 \mathrm{sec}, 72{ }^{\circ} \mathrm{C}$ for $90 \mathrm{sec}, 72{ }^{\circ} \mathrm{C}$ for $5 \mathrm{~min}$; nested PCR $94{ }^{\circ} \mathrm{C}$ for 15 min followed by 30 cycles at $94{ }^{\circ} \mathrm{C}$ for 30 $\sec 60{ }^{\circ} \mathrm{C}$ for $60 \mathrm{sec} 72{ }^{\circ} \mathrm{C}$ for $90 \mathrm{sec} 1 \mathrm{cycle}$ at $72{ }^{\circ} \mathrm{C}$ for $5 \mathrm{~min}$. The PCR was run on a thermal cycler (Applied Biosystem 2720, Singapore, S/No 272S1132046)

\section{SNP Determination at Codon 86, 184, 1034 and 1042 by Restriction Fragment Length Polymorphism}

For the PCR-RFLP methodology, the digestive enzymes used were designed to cut the DNA if mutated showing double band but if wild to remain uncut showing a single band. At the end of the round two of the nested PCR amplification of each Pfmdr1 mutation, RFLP was carried out by adding $17 \mu \mathrm{l}$ of enzyme specific for each SNP into $5 \mu \mathrm{l}$ of the nested PCR products to a volume of $22 \mu \mathrm{l}$.

The plate was properly capped and placed in an incubator (DNP 9022A, SANFA) for $16 \mathrm{~h}$ for normal digest and $45 \mathrm{mins}$ for fast digest at the respective enzymes optimum temperatures according to the manufacturer's instructions (Fermentas, Germany) (Table 3). Restriction enzyme Dra I, Dra II, Hae III and Hin Fl were used to digest codon 86, 184, 1034 and 1042 respectively (Table 3 ).

Table 3: Comparison of frequencies of Pfmdr 1 mutation in patients with good response against those with treatment failure.

\begin{tabular}{llll}
\hline $\begin{array}{l}\text { Pfmdr1 } \\
\text { mutations }\end{array}$ & $\begin{array}{l}\text { Restriction } \\
\text { enzyme }\end{array}$ & $\begin{array}{l}\text { Artemisinin resistance } \\
\mathbf{N = 5 9}\end{array}$ & $\begin{array}{l}\text { Good therapeutic } \\
\text { response } \mathbf{N}=\mathbf{5 6}\end{array}$ \\
\cline { 2 - 4 } N86Y & Dra I $^{\mathrm{a}}$ & $24(40.0)$ & Mutated (\%) \\
Y184F & Dra II $^{\mathrm{a}}$ & $26(43.9)$ & $2(3.6)$ \\
$\mathrm{S} 1034 \mathrm{C}$ & Hae III $^{\mathrm{b}}$ & $9(15.0)$ & $1(1.8)$ \\
$\mathrm{N} 1042 \mathrm{D}$ & Hin FI $^{\mathrm{b}}$ & $0(0)$ & $0(0)$ \\
Total & & $59(98.3)$ & $0(0)$ \\
\hline
\end{tabular}

The distribution of mutations among the patients that responded to treatment and those that had treatment failure. $\mathrm{N}=$ Number of patients for each treatment group; Numbers in bracket indicate the percentages for each allelic sites; ${ }^{a}=$ Normal Digest; ${ }^{\mathrm{b}}=$ Fast Digest. 


\section{Comparison of Frequencies of Pfmdr 1 Mutation in Pre -and Post-Treatment Groups}

In order to check if AL treatment had any effect on the genetic variations observed in the $P f m d r 1$ gene, samples were divided into two separate groups: Pre-treatment and post treatment group. The prevalence of the different SNPs observed in pretreatment group were analyzed and compared to that observed in the post treatment group.

\section{Gel Electrophoresis of Digested Gene}

PCR digests were electrophoresed on $2 \%$ agarose gel at 100 volts for 20-30 min. The gel was visualized under ultra-violet (UV) light on a UV Trans-illuminator (VilberLourmart, France). The bands were viewed with UV radiation blocking spectacles (USA).

\section{Statistical Analysis}

Data was analyzed using GraphPad Prism version 5.02. Descriptive statistics from the data sets include percentages, means and standard deviations and were used in comparing initial and post treatment clinical and biological characteristics (such as temperature and geometric mean parasitemia). Differences in proportions of treatment outcome and frequency in occurrence of $P f m d r 1$ gene mutation in pre-treatment and post treatment groups were analyzed using the Chi-square test or Fisher's exact test. While the differences in parasitic densities of the various groups were analyzed using ANOVA.

Genotyping data at all four $P f m d r 1$ loci were combined to determine whether the Pfmdrl N86Y-Y184F-S1034C-N1042D allele was present in pre- and post-treatment samples.

\section{RESULTS}

A total of 154 patients were sampled, 53 were males while 101 were females. Grouping of 154 sampled patients showed that 31 patients were between 6-12 years of age, 45 were 13-25 years, 30 were $26-40$ years whereas 48 were 40 years and above. Temperature readings from the sampled patients were variable but maintained a steady range $\left(35-39{ }^{\circ} \mathrm{C}\right)$ in all the patients during the 28 days follow up, although most of the patients exhibited higher temperatures at day 0 .

\section{Detection and Quantification of Plasmodium falciparum}

The Real time PCR result showed that out of the 154 patients sampled, $121(78.6 \%)$ were infected with Plasmodium falciparum while $33(21.4 \%)$ were not.

\section{Grouping of Samples Based on Responses to Treatment}

The 121 patients were grouped into 2 treatment response groups; Good therapeutic response (GTR) and artemisinin resistance (AR) group. Fifty six (46.3\%) patients that had total parasitemia clearance on days 3 and 7 post treatment without parasitemia recurrence and they were classified under GTR, while $65(53.7 \%)$ patients with increased parasite clearance time and those with recurrent parasitemia on days 14 and 28 were classified under AR group. Out of the 65 samples under AR group, 60 (92.3 $\%)$ were successfully genotyped while $5 \quad(7.7 \%)$ failed genotyping.

Comparison of Frequency of Pfmdr1 Gene in Patients with Good Therapeutic Response against Those with Artemisinin Resistance

The genotype result showed that for the GTR group, 3 $(5.3 \%)$ and $1(1.8 \%)$ had $\mathrm{N} 86 \mathrm{Y}$ and Y184F mutations respectively. There was no patient with S1034D and N1042D mutations in this group, while in the AR group, 24 (40\%), 26 $(43.9 \%)$ and $9(15 \%)$ had N86Y, Y184F and S1034C mutations respectively (Table 3). There was no patient with N1042D mutation. A total of 59 (98.3\%) out of 60 patients in AR group had one form of mutation or another. The individual mutations in the AR group were not significantly associated with treatment failure $(P>0.06)$ but the cumulative effects of the three mutations were significantly associated with treatment failure $(P>0.01)$.

\section{Patients with Co-mutation}

Furthermore, some samples showed co-mutations as they were positive for 2 SNPs. A total of $28.3 \%$ had both N86Y + $\mathrm{Y} 184 \mathrm{~F}, 5.0 \%$ had N86Y $+\mathrm{S} 1034 \mathrm{C}$ and $8.3 \%$ of the patients had S1034C + Y184F SNP respectively in the group with treatment failure. However, in the group with good treatment response, only $1.6 \%$ of the patients had co-mutation (N86Y and Y184F) (Table 4). A total of $30.0 \%$ of the patients had N86Y and Y184F form of co-mutation which was the highest in prevalence.

Table 4: Distribution of co-mutation in patients in study area.

\begin{tabular}{llll}
\hline Co-mutation & $\begin{array}{l}\text { Artemisinin } \\
\text { resistance } \\
(\mathbf{N = 5 9})^{\mathbf{a}}\end{array}$ & $\begin{array}{l}\text { Good therapeutic } \\
\text { response } \\
(\mathbf{N = 5 6})\end{array}$ & $\begin{array}{l}\text { Total } \\
(\%)\end{array}$ \\
\hline $\mathrm{N} 86 \mathrm{Y}+\mathrm{Y} 184 \mathrm{~F}^{\mathrm{b}}$ & 17 & 1 & $\begin{array}{l}18 \\
(30.0)^{\mathrm{c}}\end{array}$ \\
$\mathrm{N} 86 \mathrm{Y}+\mathrm{S} 1034 \mathrm{C}$ & 3 & 0 & $3(5.0$ \\
& & & ) \\
$\mathrm{S} 1034 \mathrm{C}+\mathrm{Y} 184 \mathrm{~F}$ & 5 & 0 & $5(8.3)$ \\
Total & 25 & 1 & 26 \\
& & & $(21.5)$
\end{tabular}

The frequency and distribution of co-mutation among the patients that responded to treatment and those that had treatment failure. ${ }^{\mathrm{a}}=$ Number of patients in each treatment group; ${ }^{\mathbf{b}}=$ Presence of more than one mutation $(\mathrm{Co}-$ mutation) in any sampled patient; ${ }^{c}=$ Percentage distribution of each comutation

\section{Comparison of Frequencies of Pfmdr 1 Mutation in Pre -and Post-Treatment Groups}

Prevalence of N86Y SNP increased significantly from 25 to $91.6 \%$, Y184F SNP from 30.7 to $92.5 \%$ and S1034C SNP from 44.4 to $100.0 \%$ in the pre-treatment to post-treatment groups respectively $(P>0.001)$ (Table 5). 


\section{DISCUSSION}

Reduced susceptibility to ACT is a major concern in Africa where Artemether-lumefantrine has been adopted as the first line drug for malaria treatment. It has been observed that drug resistance has arisen through acquisition of mutations in drug targets and in drug transporters (Gregson and Powel, 2005). In Nigeria AL has been widely used for the treatment of uncomplicated malaria following its adoption as first line treatment in 2005; Consequently, there have been locally generated reports from Nigeria suggesting reduced responses to and /or emerging resistance to artemisinin combination therapies (Ayogu et al., 2015; Ukwe et al., 2010; Happi et al., 2009). In this study we present the involvement of SNPs in Pfmdr 1 gene in artemisinin resistance using malaria patients treated with AL therapy in Enugu South East Nigeria, focusing on the difference in the genetic variations in the Pfmdr 1 gene of patients that had good therapeutic response (GTR) and those that showed artemisinin resistance (AR).

For the purpose of this study, patients were monitored and evaluated on days $0,3,7,14$ and 28 because the presence of day 3 parasitemia is the most useful method for assessing artemisinin resistance in mobile patients (Vredan et al., 2013) and it requires less frequent blood sampling (Stepniewska et al., 2010; White, 2011). Over half of the patient population screened in this study had variable mutations at one codon of the Pfmdr 1 gene or the other. This high prevalence of Pfmdr 1 mutations suggests the possibility of ancient clones of $P$. falciparum with reduced susceptibility to artemisinin derivatives in the study area. This result also confirms the prevalence of these mutations in the study area.

In classifying study patients into GTR and AR we considered the following; WHO working definition of artemisinin resistance as an increase in parasite clearance time as evidenced by $\geq 10 \%$ of cases with parasites detectable on day 3 after treatment with an ACT (WHO, 2013), that AL is known for rapid parasitemia clearance by the quick onset of action of artemether and a sustained parasitemia clearance by the longer acting action of lumefantrine, and finally that artemisinins are highly active against young circulating ring-stage parasite before cytoadherence occurs. The presence of parasitemia on day 3 post infection has been used as an indicator of reduced sensitivity of $P$. falciparum parasite to treatment with artemisinin derivatives [32]. Consequently, all patients with increased parasite clearance time and hence having presence of parasitemia on day 3 and 7 and those with recurrent parasitemia on day 14 and 28 were all grouped under AS group, while patient with total parasite clearance on day 3 and 7 post treatment without parasitemia recurrence on day 14 and 28 were classified under GTR group.

Analysis of the results done showed that almost all the patients that had artemisinin resistances which were genotyped had one form of Pfmdr $1 \mathrm{SNP}$ or another with the most common allele being N86Y and Y184F. This is indicative of a gradual gaining of stability of these genotypes in Enugu Nigeria. Comparing this result with previously reported cases in Nigeria and beyond, Happi et al.,2009 recorded a higher prevalence of Pfmdr 1 Y184F in their study while Menard et al., 2006reported a lower prevalence of Pfmdr 1 N86Y allele. In this study, Pfmdr 1 S1034C allele was also observed but occurred at a lower frequency compared to Pfmdr 1 N86Y and Y184F while Pfmdr 1 N1042D allele was not observed in any of the patients tested. The absence of N1042D allele within the study group could not be explained, however a similar finding has been reported in other studies Dokomajila et al., 2006; Happi et al.,2009 while our result differs from another study carried out in Ghana, where the prevalence of Pfmdr 1 N1042D allele was found to increase from 2003-2010 (Duah et al., 2013). It is worthy of note that it is the cumulative rather than individual effect of these Pfmdr 1 SNPs that contributed significantly $(\mathrm{P}<0.001)$ to artemether-lumefantrine resistance. On the other hand, the analysis of patients with good therapeutic response resulted in very low frequency of Pfmdr 1 N86Y and Y184F allele. None of the patients under this category had either S1034C or N1042D SNPs. The occurrence of Pfmdrl mutation in this group of patients might be due to incomplete AL treatment before enrolment which possibly had subjected the Plasmodium to sub therapeutic dose level of AL. It is also possible that the mutation in Pfmdrl gene may not be the only mechanism of AL resistance by Plasmodium falciparum.

It was also observed that some patients were positive for more than one mutation in Pfmdr 1 which was regarded as comutation. The prevalence of $\mathrm{N} 86 \mathrm{Y}+\mathrm{Y} 184 \mathrm{Y}$ mutation was higher than that of $\mathrm{N} 86 \mathrm{Y}+\mathrm{S} 1034 \mathrm{D}$ and $\mathrm{Y} 184 \mathrm{~F}+\mathrm{S} 1034 \mathrm{C}$. The prevalence of Pfmdr 1 co-mutation was higher in the AR group than in the GTR group, even though a few patients who responded to treatment had co-mutation. The prevalence of co-mutation may be due to the fact that in areas of high endemicity of $P$. falciparum, human host are often super infected with multiple clones of the parasite (Smith et al., 1999). Pfmdr 1 N86Y+Y184F co-mutation significantly contributed to AL resistant $(\mathrm{P}<0.001)$. This occurrence of parasite with Pfmdr 1 co-mutation is a threat to artemisinin therapy.

Evaluating the prevalence of mutations in the Pfmdr 1 gene at the baseline (day 0) and comparing it with follow up days post treatment, it was observed that there was a significant $(\mathrm{P}<0.001)$ increase from pre-treatment to post-treatment prevalence of Pfmdr 1 N86Y, Y184F and S1034C allele. Our data also revealed that before exposure to AL therapy, most of the Pfmdr 1 genes were wild type while soon after introduction of AL very few remained wild type while majority of them were mutated. This implies that the presence of the AL induced genetic variations in the Pfmdr 1 gene. The increase in the prevalence of the Pfmdr1 N86Y and Y184F alleles that we observed after AL treatment compared to the prevalence in the baseline population could possibly result from $P$. falciparum undergoing genetic/structural changes as a defense mechanism for survival during AL therapy or that these alleles were selected for on a population level but not on an individual level with the recent increase in the use of $\mathrm{AL}$ at the study site. It could also be that in AL-treated patients, lumefantrine 
might have selected parasites harboring the Pfmdr1 N86Y and Y184F alleles or the Pfmdr1 haplotype in new infections emerging from the liver after clearance of artemether. Our study is in agreement with another work done at Uganda which reported significant increase in the prevalence of Pfmdr 1 N86Y and Y184F alleles from pretreatment samples to post treatment $(\mathrm{P}>0.0001)$ (Dokomajilar et al., 2006) Another report from Zanzibar (Sowunmi et al., 2007) showed a significant accumulation of Pfmdr 1 N86 and Y184 alleles among patients who had parasites after AL treatment. There are some limitations inherent in this work and the results are analyzed as such. Our study did not differentiate recrudescence from reinfection by genotyping with the view of observing the strength of AL in protecting a patient for up to 28 days in an area of high endemicity and samples were not sequenced to confirm the presence of SNPs as reported. However, further studies are needed to obtain the sequences of the Pfmdrl gene in this parasite population

\section{CONCLUSION}

In conclusion, our study has demonstrated that that there is high prevalence of Pfmdr $1 \mathrm{~N} 86 \mathrm{Y}$ and F184Y and that the prevalence of mutated alleles of $P f m d r 1$ is higher in patients who had artemisinin resistance than in those who had good response hence is strongly associated with artemisinin resistance in Enugu, Nigeria.It has also shown that presence of artemether-lumefantrine treatment induced genetic variation in the Pfmdr 1 gene.

\section{ACKNOWLEDGEMENT}

The authors are grateful to the patients who accepted to willingly participate in this research work, they also acknowledge the efforts of the staff and managements of District Hospital Nsukka, Bishop Shanahan Hospital, Enugu-Ezike, Cottage Hospital Ugbuawka, Safety Molecular Pathology Laboratory, Enugu (SMPL) for their support during the work. The staff and management of the Department of Clinical Pharmacy and Pharmacy management, Faculty of Pharmaceutical Sciences, University of Nigeria Nsukka are also greatly acknowledged.

\section{REFERENCES}

Ayogu EE, Ukwe CV, Nna EO. Therapeutic efficacy of Artemether-lumefantrine for treatment of uncomplicated Plasmodium falciparum malaria in Enugu, Nigeria. Trop J Pharm Res, 2015;14(8):1487-93.

Dokomajilar C, Nsobya SL, Greenhouse B, Rosenthal PJ, Dorsey G. Selection of Plasmodium falciparum Pfmdr1 alleles following therapy with artemether-lumefanthrine in an area of Uganda where malaria is highly endemic. Antimicrob Agents Chemother, 2006;50: 1893-5.

Duah NO, Matrevi SA, de Souza DK, Binnah DD, Tamakloe MM, Opoku VS, et al. Increased Pfmdrl gene copy number and decline in Pfcrt and Pfmdrl resistant alleles in Ghananian Plasmodium falciparum isolates after the change of antimalarial drug treatment policy. Malar J, 2013;12: 377-86

Duraisingh MT, Cowman AF. Contribution of Pfmdr 1 gene to antimalarial drug-resistance. Acta Trop, 2005;94(3):181-90.

Duraisingh MT, Jones P, Sambou I, von Seidlein L, Pinder M, Warhurst DC. The tyrosine-86 allele of the Pfmdr 1 gene of Plasmodium falciparum is associated with increased sensitivity to the anti-malarials mefloquine and artemisinin. Mol Biochem Parasitol, 2000a;108:13-23.

Ekanem OJ, Ezedinachi EN, Molta NB, Watila IM, Chukwuani $\mathrm{CM}$, Meremikwu MM et al. Treatment of malaria in North-Eastern and South-Eastern Nigeria: a population study of mefloquine, sulphadoxine, pyrimethamine combination (MSP) vs chloroquine (CQ) West Afr J Med, 2000;19(4): 293-7.

Ezedinachi ENU, Alaribe AA, Meremikwu MM, Ejezie GC. New trends in Chloroquine efficacy in the treatment of malaria. Central Afr J Med, 1992; 38: 303-7.

Falade C, Makanga M, Premji Z, Ortmann CE, Stockmeyer M, de Palacios PI. Efficacy and safety of artemether-lumefanthrine (coartem) tablets (six dose regimen) in African infants and children with acute uncomplicated malaria. Trans R Soc Trop Med Hyg, 2005;99: 459-69.

Falade CO, Salako LA, Sowunmi A, Oduola AMJ, Larcier P. Comparative efficacy of halofanthrine, Chloroquine and sulfadoxinepyrimethamine for treatment of acute uncomplicated malaria in Nigerian children. Trans R Soc Trop Med Hyg, 1997;91:58-62.

Federal Ministry of Health, Nigeria. National Antimalarial Treatment Policy, May 2005:1-30

Gregson A, Plowe, CV. Mechanisms of resistance of malaria parasites to antifolates. Pharmacol Rev, 2005;57: 117-45.

Guerra CA, Snow RW, Hay SI. Mapping the global extent of malaria in 2005. Trends Parasitol, 2006; 22(8): 353-8.

Happi CT, Gbotosho GO, Folarin OA, Sowunmi A, Hudson T, O'Niel MW, et al. Selection of Plasmodium falciparum multidrug resistant gene 1 allele in asexual stages and gametocytes by artemetherlumefantrine in Nigerian children with uncomplicated falciparum malaria. Antimicrob Agents Chemother, 2009;55: 888-95.

Hay S, Okiro E, Gething P, Patil A, Tatem A, Guerra C, Snow RW. Estimating the global clinical burden of Plasmodium falciparum. Malaria PLoS Med, 2007; 7(6):e10000290.

Hay SI, Guerra CA, Tatem AJ, Noor AM, Snow RW. The global distribution and population at risk of malaria: past, present, and future. Lancet Infect Dis, 2004; 4(6): 327-36.

Jambou R, Legrand E, Niang M, Khim N, Lim P, Volney B, et al. Resistance of Plasmodium falciparum field isolates to in vitro artemether and point mutations of the SERCA - type PfATPase 6. Lancet. 2005;336(9501): 1960-3.

Mayxay M, Pukrittayakamee S, Newton PN, White NJ. Mixed Specie malaria infections in humans. Trends Parasitol, 2004; 20(5): 233-40.

Menard D, Djalle D, Yapou F, Manirakiza A, Talarmin A. Frequency distribution of antimalarial drug resistant alleles among isolates of Plasmodium falciparum in Bangui Central African Republic. Am J Trop Med Hyg, 2006;74(2):205-10

Noedl H, Se Y, Sriwichai S, Schaecher K, Teja-Isavadharm P, Smith B, et al. Artemisinin resistance in Cambodia: a clinical trial designed to address an emerging problem in Southeast Asia. Clin Infect Dis, 2010;51(11):e82-89 doi: 10.1086/657120.

Nosten F, White NJ. Artemisinin-based combination treatment of falciparum malaria. Am J Trop Med Hgy, 2007;77(6 suppl): 181-92.

Onwujekwu O, Hanson K, Fox-Rushby J. Inequalities in purchase of mosquito nets and unwillingness to pay for insecticide- treated nets in Nigeria: Challenges for malaria control Interventions. Mal J, 2004;3:6 doi:10.1186/1475-2875-3-6

Orjih A, Cherian P, Alfadhli S. Microscopic Detection of Mixed Malarial Infections: Improvement by Saponin Hemolysis. Med Princ Pract, 2008;17(6): 458-63. doi:10.1159/000151567).

Rohrbach P, Sanchez CP, Hayton K, Friedrich O, Patel J, Sidhu ABS, Ferdig MT, Fidock DA, Lanzer M. Genetic linkage of pfmdr1 with food vacuolar solute import in Plasmodium falciparum. EMBO J, 2006;25(13): 3000-11.

Sisowath C, Stromberg J, Martensson A, Msellem M, Obondo C, Bjorkman A, et al. Invivo selection of Plasmodium falciparum Pfmdr1 $86 \mathrm{~N}$ coding alleles by artemether-lumefanthrine (coartem). J Infect Dis, 2005;191(6): 1014-7.

Smith T, Felger I, Fraser-Hurt N. Beckh. Effect of insecticide treated bed nets on the dynamics multiple Plasmodium falciparum. Trans Roy Soc Trop Med Hyg, 1999; 93 (suppl 1): 53-57 
Snow RW, Guerra CA, Noor AM, Myint HY, Hay SI. The global distribution of clinical episodes of Plasmodium falciparum malaria. Nature, 2005;434(7030): 214-7.

Sowunmi AGO, Gbotosho CT, Happi AA, Adedeji FA, Fehintola OA, Folarin E, et al. Therapeutic efficacy and effects of artemether-lumefantrine and amodiaquine-sulfadoxine-pyrimethamine on gametocyte carriage in children with uncomplicated Plasmodium falciparum malaria in southwestern Nigeria. Am J Trop Med Hyg, 2007; 77:235-41.

Stepniewska K, Ashley E, Lee SJ, Anstey N, Barnes KI, Binh $\mathrm{TQ}$, et al. In-vivo parasitological measures of artemisinin susceptibility. J Infect Dis, 2010; 201(4): 570-9. doi: 10.1086/650301

Thompson TT, Ishenggoma DS, Mmbando BP, Lusingu JP, Vestergaard LS, Threander TG, et al. Prevalence of single Nucleotide polymorphisms in Plasmodium falciparum gene Multidrug resistance gene $(P f m d r 1)$ in Korogwe District in Tanzania before and after introduction of artemisinin-based combination therapy. Am J Trop Med Hyg, 2011; 85(6):979-83

UK Aid Department for International Development. Malaria: Burden and Interventions: Evidence Overview - A Working Paper, 2010 (Version 1.0).

Ukwe CV, Ekwunife OI, Ayogu EE, Adibe MO. Cost Effectiveness of Artemether-lumefanthrine, artesunate-amodiaquine and dihydroartemisinin-piperaquine in the treatment of uncomplicated malaria in Nigerian patients. Drug Invention Today. 2010;2(10): 429-32.

Vreden GS, Jitan JK, Bansie RD, Adhin MR. Evidence of an increased incidence of day 3 parasitemia in Suriname: an indicator of the emerging resistance of Plasmodium falciparum to artemether. Mem inst osmaldo Cruz, Rio de Janeiro, 2013; 108: 968-73.
White NJ. Plasmodium knowlesi: The fifth human malaria parasite. Clin Infect Dis, 2008; 46(2): 172-3.

85.

White NJ. The parasite clearance curve. Malar J, 2011;10:278-

World Health Organization. Emergency response to artemisinin resistance in Greater Mekong sub region: Regional framework for action 2013-2015. WHO 2013:10.

Yang H, Liu D, Yang Y, Fan B, Yang P, Li X, et al. Changes in susceptibility of Plasmodium falciparum to artesunate in vitro in Yunnan Province, China. Trans R Soc Trop Med Hyg, 2003;97: 226-8.

Yeka A, Dorsey G, Kamya MR, Talisuna A, Lugemwa M, Rwakimari JB, Staedke SG, Rosenthal PJ, Wabwire-Mangen F, Bukirwa $\mathrm{H}$. Artemether-lumefanthrine vs dihydroartemisinin-piperaquine for treating uncomplicated malaria: a randomized trial to guide policy in Uganda, PLoS One, 2008;3(6):e2390.doi:10.1371/journal.pone.0002390.

Zurovac D, Tibenderana JK, Nankabirwa J J, Ssekitooleko J, Njogu NJ, Rwakimari J.B et al. Malaria case management under artemether-lumefanthrine treatment policy in Uganda. Mal J, 2008;7:181. doi: $10.1186 / 1475-2875-7-181$

\section{How to cite this article:}

Ayogu EE, Ukwe CV, Mgbeahurike AC, Nna EO. Prevalence of Pfmdr1 86y and 184f Alleles is Associated with Recurrent Parasitemia Following Treatment of Uncomplicated Malaria with Artemether-Lumefantrine in Nigerian Patients. J App Pharm Sci, 2016; 6 (04): 015-021. 